\title{
Parents' and children's reactions to taking blood in a nutrition survey
}

\author{
P S W Davies, D L Collins, J R Gregory, P C Clarke
}

\begin{abstract}
Objective-To assess the reactions of parents and their children to the request for a blood sample and an attempt to take blood.

Methods-1859 children aged 1.5-4.5 years took part in a national survey of diet and nutrition. A retrospective inquiry of the parents' and children's reported reactions was carried out six to 18 months later by postal questionnaire sent only to the 1157 who had given consent for an attempt to take blood.

Results-866 questionnaires were returned; 790 were from parents of children in whom an attempt to take blood had been successful. Thirteen per cent said that their child had given blood previously. About $30 \%$ discussed the request with the family doctor or nurse. Some $\mathbf{9 0 \%}$ said that they were given enough information and that the phlebotomist was sympathetic. Attempting to take blood caused upset in over $50 \%$, which, in most, lasted for less than five minutes. A substantial minority were upset for up to 30 minutes and a few for much longer. Bruising or bleeding occurred in $20-27 \%$. Degree and duration of upset were both adversely associated with a failed attempt to obtain blood.

Conclusion-The majority of preschool children experienced no more than a little upset of short duration after an attempt to take blood, but a substantial minority exhibited a greater degree of upset. These responses should be taken into account when assessing the benefits and risks of the procedure. The best equipment and expertise should be employed for taking blood as successful attempts are less upsetting.

(Arch Dis Child 1996;75:309-313)
\end{abstract}

Keywords: taking blood, distress, bruising.

In 1992-3, a national survey of the diet and nutrition of British children aged 1.5-4.5 years included asking for a blood sample. ${ }^{1}$ This article describes the reactions of the children and their carers to an attempt to take blood as assessed by a postal questionnaire sent retrospectively. Parents who gave consent for taking blood in the survey were approached for this follow up study; the attitudes of the children and their parents who refused consent were not examined.

\section{Background}

Nutritional surveys provide information about the diet consumed and nutrient intake. These data can be correlated with socioeconomic factors and with outcome measures of nutritional status such as height and weight. Population groups with nutrient intakes below defined reference levels can be characterised. Surveys also provide data to examine relations among diet, nutrition, health, morbidity, and cause of death, especially if the study is longitudinal. A sample that is nationally representative of the whole population can be selected with the appropriate techniques.

Traditionally, nutrition studies have collected questionnaire and dietary record data with anthropometric measurements. Recently, the importance of analysing blood has been acknowledged, and the value of surveys without accompanying blood analysis is now regarded as limited. It was therefore decided that the National Diet and Nutrition Survey of Children aged 1.5-4.5 years would include a request to take a blood sample. ${ }^{1}$ Blood analysis would, firstly, monitor nutritional status in general and assess status where deficiencies, such as vitamin $D,{ }^{2}$ had been identified in earlier decades; secondly, provide prevalence data about common nutritional disorders such as iron deficiency anaemia ${ }^{3}$; thirdly, provide nationally representative data to establish reference ranges for blood analytes, which are useful for public health and clinical services; and finally, offer the benefit of early identification of treatable conditions, such as anaemia and hyperlipidaemia, to affected individuals.

Taking a blood sample adds to the complexity of a diet and nutrition survey. Individuals may decline to take part in the survey if they know that they will be asked to provide blood, which may compromise the representativeness of the sample. Fieldworkers may be unfamiliar with procedures for taking and handling a blood sample, and the survey team may not have access to a laboratory competent to carry out the analyses. The difficulties of including a blood sample in a diet and nutrition survey are greater if the participants are children, especially if very young. Parents and carers, as well as the survey fieldworkers, are protective of children, particularly when they are too young to give informed consent.

The fieldwork for the survey, which was commissioned jointly by the Department of Health and the Ministry of Agriculture, Fisheries and Food, was carried out by the Social Survey Division of the Office for National Statistics (ONS) during the 12 month

Dr Clarke. 
period beginning July 1992. The Medical Research Council Dunn Nutrition Unit (DNU) was responsible for taking and analysing the blood. The elements of the survey included collecting social and demographic data, a four day weighed dietary record, height and weight measurements, and obtaining a sample of blood. A full description of the survey methodology and results has been reported elsewhere and includes a description of seeking consent from local research ethics committees, the approach to parents, consent and confidentiality aspects, and handling of the results. ${ }^{1}$ All blood samples were taken in the child's home and the procedures are described in detail. The survey took advantage of the specialised phlebotomy services, which have developed in recent years to take blood from very young children, and of up to date equipment. Consent was given by $63 \%$ of parents for taking a blood sample. A blood sample was successfully obtained from $87 \%$ of these children, which represents $54 \%$ of the total of 1859 children from whom dietary data had been collected. The phlebotomist chose the site for attempting to take blood. The most common site was the antecubital fossa but the back of the hand and finger prick were also used. The protocol allowed only two attempts to obtain blood, and a maximum volume of 4 $\mathrm{ml}$.

Parents were told from the outset that they would be asked to provide consent for their child to give a blood sample. This early approach sought to ensure that the decision to consent was a free one, and that it was not influenced by personal rapport or a sense of obligation, which might tend to be established between the parents and the survey team during the period of contact. Consent included taking a blood sample, releasing the results of analysis to the child's doctor, and storing residual blood. On advice from those with extensive experience of taking blood from young children, it was decided not to use local anaesthetic cream unless local ethics committees insisted. Safeguards for confidentiality meant that only ONS knew the names and addresses of those participating in the survey. When parental consent had been obtained, the participants' names and addresses were sent to the DNU which arranged to take the blood sample.

\section{Follow up of reactions to taking blood: participants and methods}

As a first step, the Office of Population Censuses and Surveys wrote to parents who had given consent between six and 18 months previously to taking a blood sample. They were asked whether they would agree to the follow up study and to being sent a questionnaire. This letter was sent to the last known address, but some children had moved and could not be contacted.

Questionnaires were sent only to parents who agreed to take part in this review of the blood sampling procedures. Parents were asked to respond to each question by ticking a box from a series of optional answers. The same information was collected from all parents.

The key elements of the questionnaire were:

(A) Whether the parents had expected to be asked to agree to a sample of their child's blood being taken as part of a survey of diet;

(B) Whether the information and explanation provided by the research team had been adequate, and who they had turned to for further discussion;

(C) Whether it had been discussed with the child beforehand;

(D) The child's reaction at the time of attempting to take a sample of blood;

(E) The rapport of the phlebotomist with the child and the skill in obtaining the sample;

(F) The immediate outcome if the child was upset or not, and the long term outcome in terms of bruising and bleeding;

(G) An assessment of what the child's response might be to future attempts to take blood;

(H) The parent's assessment of whether or not they were pleased that they had given consent, or had no particular response.

If no reply had been received to the questionnaire in four weeks, two further attempts were made by letters to encourage the parents to complete and return the questionnaire. The questionnaires were analysed using the Minitab statistical package. ${ }^{4}$

\section{Results}

A total of 1157 parents gave consent for blood to be taken in the original diet and nutrition survey. An attempt was made in 1102 children. There was no attempt to obtain blood from 55 children, although consent had been obtained. This decision was at the discretion of the phlebotomist who was instructed not to attempt venepuncture if the child was overtly distressed at the time of the appointment. Table 1 shows the number of attempts to obtain a blood sample (maximum of two) and the sites of sampling. Blood was obtained at the first attempt in $912(79 \%)$ of a total of 1157 children. The antecubital fossa was used in $82 \%$ of successful first attempts. The amount of blood obtained in $70 \%$ of all attempts was 3 $\mathrm{ml}$ or more.

Some 866 of the 1157 parents contacted for the retrospective study returned a completed questionnaire; 790 concerned children in whom the attempt to take blood had succeeded and 76 in whom it had not. No significant difference was found between the responders and the non-responders with respect to the age of the child or socioeconomic group as assessed by the fathers' occupations.

Thirteen per cent of the 866 questionnaires returned reported that the child had given a blood sample before (table 2). Responses to questions are shown separately depending on whether or not blood was obtained. Twenty per cent of families were very surprised that a blood sample was requested as part of a nutritional survey. Some $75 \%$ of families were either not surprised or a little surprised by the 
Table 1 Outcome of an attempt to take a blood sample (1157 parents gave consent); values are number (\%)

\begin{tabular}{lcc}
\hline & \multicolumn{2}{l}{ No of children who undervent venepuncture } \\
\cline { 2 - 3 } Outcome & First attempt & Second attempt \\
\hline Blood obtained $1003(87)$ & & \\
First attempt 912(91) & $749(82)$ & \\
ACF & $106(12)$ & \\
BH & $56(6)$ & \\
FP & 1 & \\
NK & $75(83)$ & $48(53)$ \\
Second attempt 91 (9) & $12(13)$ & $13(14)$ \\
ACF & 0 & $27(30)$ \\
BH & $4(4)$ & $3(3)$ \\
FP & & \\
NK & $65(88)$ & \\
Blood sampling procedure attempted but unsuccessful $99(8)$ & $8(11)$ & \\
First attempt 74 ( 75) & $1(1)$ & \\
ACF & $23(92)$ & $22(88)$ \\
BH & $1(4)$ & $1(4)$ \\
NK & $1(4)$ & \\
ACF & & \\
BH & & \\
NK & & \\
Blood sampling procedure not attempted 55 (5) & & \\
\hline
\end{tabular}

ACF = antecubital fossa; $\mathrm{BH}=$ back of the hand; FP = finger prick; NK = not known.

request. Almost $90 \%$ of families felt that the information provided was adequate. About $30 \%$ had discussed the request for a blood sample with a health professional such as their doctor or a nurse. Fifty five per cent of families had talked about taking blood with the child. Ninety per cent of the responders felt that the phlebotomist was sympathetic to their child's fears about taking blood. Ninety three per cent of responders felt that the phlebotomist was either very good or good in the manner in which taking blood was attempted.

\section{Upset caused by taking blood}

Children were more often upset if the attempt to take blood was unsuccessful (table 3).

Table 2 Follow up of reactions to taking blood (total No of children 866). Parents reported reactions to the request for a blood sample

\begin{tabular}{|c|c|c|}
\hline \multirow[b]{2}{*}{ Question/reply } & \multicolumn{2}{|c|}{ Blood sample (\%) } \\
\hline & $\begin{array}{l}\text { Obtained } \\
(n=790)\end{array}$ & $\begin{array}{l}\text { Not obtained } \\
(n=76)\end{array}$ \\
\hline \multicolumn{3}{|c|}{$\begin{array}{l}\text { Had your child ever given a blood sample before (excludes at birth and in neonatal } \\
\text { period)? }\end{array}$} \\
\hline $\begin{array}{l}\text { Yes } \\
\text { No }\end{array}$ & $\begin{array}{l}13 \\
87\end{array}$ & $\begin{array}{l}13 \\
87\end{array}$ \\
\hline \multicolumn{3}{|c|}{$\begin{array}{l}\text { What was your first reaction when you were asked if your child would give a blood } \\
\text { sample as part of a study of what your child eats? }\end{array}$} \\
\hline Very surprised & 20 & . 24 \\
\hline A little surprised & 51 & - 61 \\
\hline Not surprised & 23 & 13 \\
\hline Expected to be asked & 4 & 2 \\
\hline Can't remember & 2 & 0 \\
\hline \multicolumn{3}{|c|}{ Were you given enough information? } \\
\hline Yes & 90 & 85 \\
\hline No & 7 & 1 \\
\hline Can't remember & 3 & 14 \\
\hline \multicolumn{3}{|c|}{ Did you discuss the blood sample with a family doctor/nurse/etc? } \\
\hline Yes & 32 & 15 \\
\hline No & 65 & 84 \\
\hline Can't remember & 3 & 1 \\
\hline \multicolumn{3}{|c|}{ Did you or any of your family or friends talk to your child beforehand? } \\
\hline Yes & 56 & 55 \\
\hline No & 42 & 41 \\
\hline Can't remember & 2 & 4 \\
\hline \multicolumn{3}{|c|}{$\begin{array}{l}\text { Do you think that the blood taker was sympathetic to any fears that your child might } \\
\text { have had about giving blood? }\end{array}$} \\
\hline Yes & 90 & 96 \\
\hline No & 7 & 3 \\
\hline Can't remember & 3 & 1 \\
\hline \multicolumn{3}{|c|}{ What did you think about the way in which the blood taker tried to take blood? } \\
\hline Very good & 56 & 34 \\
\hline Good/satisfactory & 37 & 56 \\
\hline Poor & 4 & 12 \\
\hline Very poor & 2 & 1 \\
\hline Can't remember & 1 & 0 \\
\hline \multicolumn{3}{|c|}{ In the future, when meeting doctors and nurses, do you think your child will be: } \\
\hline More confident & 19 & 17 \\
\hline Less confident & 10 & 19 \\
\hline No different & 71 & 64 \\
\hline \multicolumn{3}{|c|}{$\begin{array}{l}\text { Looking back now, how do you feel about giving consent for a blood sample to be } \\
\text { taken? }\end{array}$} \\
\hline Pleased & 58 & 32 \\
\hline Regret & 9 & 26 \\
\hline No feelings & 33 & 42 \\
\hline
\end{tabular}


Table 3 Taking the blood sample: reported problems (total No of children 866)

\begin{tabular}{lcc}
\hline & \multicolumn{2}{c}{ Blood sample (\%) } \\
\cline { 2 - 3 } Question/reply & Obtained & Not obtained \\
\hline What was your child's immediate reaction during attempt to take & & \\
blood? & 22 & 57 \\
Very upset & 35 & 30 \\
A little upset & 42 & 12 \\
Not upset & 1 & 1 \\
Can't remember & \\
If your child was upset, for how long did this last? & 62 & 37 \\
< 5 min & 28 & 49 \\
$5-30$ min & 4 & 6 \\
$30-60$ min & 2 & 3 \\
Several hours & 4 & 5 \\
Several days & 0 & 0 \\
Can't remember & & \\
Did the attempt to take blood cause a bruise? & 27 \\
Yes & 66 & 58 \\
No & 10 & 15 \\
Can't remember & & \\
Was there any bleeding after the blood sample was taken? & 20 & 23 \\
Yes & 73 & 67 \\
No & 7 & 10 \\
Can't remember & & \\
\hline
\end{tabular}

Where children were reported to have been a little upset or very upset the length of the distress seemed to be influenced by the occurrence of bleeding or bruising, or both (table 4). Of the 171 children who were reported to be very upset, 49 were upset for less than five minutes, 79 for five to 30 minutes, and 43 for longer than 30 minutes. The degree of upset experienced by the child did not relate to whether the parent or another family member discussed the venepuncture before attendance of the phlebotomist. Nineteen per cent of parents who discussed the blood sampling procedure with their child reported that their child was very upset after venepuncture and $25 \%$ who had not discussed the procedure said that their child was similarly upset $\left(\chi^{2}=3.48,3 \mathrm{df}\right)$. The number of children who had local anaesthetic cream applied before the attempt to take blood was too few for separate analysis. The protocol required no more than two attempts. Fieldworkers reported that some parents were themselves disappointed when two attempts failed, and appeared to want the phlebotomist to try again in the hope that the success in obtaining blood would make it worthwhile.

Ten per cent of responders felt that the attempt to take blood might cause their child to be less confident in the future when meeting health professionals (table 2). Seventy per cent of families felt that the procedure had had no effect on their child's confidence, while the remaining $20 \%$ felt that their child might be more confident in the future.

\section{Discussion}

The national diet and nutrition survey, which covers the whole population aged over 1.5 years, has been developed in accord with

Table 4 Duration of upset in relation to reported bruising and/or bleeding

\begin{tabular}{llllll}
\hline \multirow{2}{*}{ Trauma if any } & \multicolumn{5}{c}{ Children reported as being upset (total 516): How long was your child upset? (\%) } \\
\cline { 2 - 6 } & $<5$ min & $5-30$ min & $30-60$ min & Several hours & Several days \\
\hline Bruising & 40 & 43 & 6 & 3 & 8 \\
No bruising & 71 & 20 & 5 & 1 & 3 \\
Bleeding & 39 & 44 & 6 & 3 & 8 \\
No bleeding & 68 & 23 & 4 & 1 & 4 \\
\hline
\end{tabular}

guidelines on research on healthy volunteers prepared by a working party of the Royal College of Physicians in $1986 . .^{5}$ Particular emphasis is placed on explaining the survey at the outset, providing a written account for individuals to keep, obtaining consent throughout the procedures including consent to inform their doctor, and on safeguards for confidentiality. It was reassuring that almost $90 \%$ of families considered retrospectively that they had received adequate information to make an informed decision. The guidelines acknowledge that there may be minimal risk from minor procedures such as blood sampling, collecting urine or measuring body dimensions. The level of risk justified in non-therapeutic research, assuming that participating is less likely to offer individual benefit, should be no more than minimal.

In 1980 the British Paediatric Association (BPA) issued guidelines to aid ethics committees considering research involving children. ${ }^{6}$ The distinction was made between therapeutic and non-therapeutic research. The guidelines acknowledged four premises:

(1) That research involving children is important for the benefit of all children and should be supported and encouraged and conducted in an ethical manner;

(2) That research should never be done in children if the same investigation can be done in adults;

(3) That research that involves a child and is of no benefit to the child is not necessarily unethical or illegal;

(4) The degree of benefit resulting from the research should be assessed in relation to the risk of disturbance, discomfort, or pain-the risk:benefit ratio.

These were reviewed by the BPA and further guidance for the ethical conduct of medical research involving children was published in $1992^{7}$ and $1993 .{ }^{8}$ These guidelines $(1980,1992$, and 1993) encouraged evaluation of the nature and balance of benefits and risks of a research procedure. It was predicted from the diet and nutrition survey of preschool children that a proportion of children would benefit as a result of blood analysis. Unsuspected deficiencies of nutrients, such as iron, vitamin $D$, vitamin $A$ and others, would be identified as well as unsuspected health disorders such as familial hyperlipidaemia. In the present study $8 \%$ of children from whom a blood sample was obtained had haemoglobin concentrations below $110 \mathrm{~g} / 1$, and the parents were informed as was the child's doctor (provided that parental consent to inform had been obtained). There might also be benefit if, through familiarisation with healthcare procedures, the child becomes more confident. Moreover, while not personal to the individual child, the new information gained would be expected to lead to an improved understanding of nutrition in this age group, and hence to better focused nutrition policies and better informed clinical services for the whole population of children under 5 years in this country.

The risks of attempting to take blood include upset to the child and to the parents due to 
pain or fear, and bruising or bleeding. These results confirm that, where the attempt to take blood was successful, many children aged $1.5-4.5$ years suffered, at most, only minor degrees of upset, although some parents reported their children as having been very upset but usually for a short duration. Upset was greater and more prolonged when blood was not obtained and this was more likely if there was bruising or bleeding.

In preparing for the blood sampling element in this survey of diet and nutrition every effort was made to ensure that good practices were adopted including adherence to the relevant guidelines for research, the expertise of the phlebotomist, and the quality of the blood taking equipment. The dietary fieldworkers were responsible for obtaining consent for taking blood. All were trained and experienced and gave support to the parents who usually enjoyed cooperating with the study and seemed to recognise that the questions asked were important and relevant to the health of all children under 5 years. This professionalism gave most parents the confidence to consent to an attempt to take blood. When the dietary fieldworker had obtained consent, an expert paediatric phlebotomist visited the home. A critical determinant in minimising upset and duration of upset was whether the attempt to take blood was successful without bleeding or bruising. This confirms the importance of employing phlebotomists with the highest expertise. All survey staff had a responsibility for enabling parents and children to withdraw from the procedure if one or both changed their minds, or the child was, for instance, unwell.

In assessing the significance of the results of blood analyses, as blood was obtained from only $54 \%$ of the whole group, it cannot be assumed that results from this proportion can be extrapolated to the whole group and hence to the British population without further analysis of the characteristics of the group of children giving blood, compared with those of the group as a whole. The characteristics for comparison in this survey, which was designed to be nationally representative, include age, sex, social class of the head of household, and region. The authors believe that, provided the data are handled appropriately, which may involve weighting, the results of the blood analysis make a significant contribution to the available information about preschool children in this country. Further, assessment of reactions to taking blood confirms that risks to individual participants and the population as a whole did not outweigh the benefits expected from this survey.

We thank the parents and children for their cooperation. This work received financial support from the Department of Health. The National Diet and Nutrition Survey of Children aged 1.54.5 years was funded jointly by the Ministry of Agriculture Fisheries and Food and the Department of Health conducted by the social survey division of the Office for National Statistics in conjunction with the DNU.

1 Gregory JR, Collins DL, Davies PSW, Hughes JM, Clarke PC. National diet and nutrition survey: children aged 1.5 to 4.5 years. Volume 1: report of the diet and nutrition survey. London: HMSO, 1995.

2 Department of Health and Social Security. Rickets and osteomalacia. Report on Health and Social Subjects No 19. malacia. Report on Heald
London: HMSO, 1980.

3 Department of Health. Weaning and the weaning diet. Report on Health and Social Subjects No 45. London: HMSO, 1994.

4 Minitab. Reference manual. 3081 Enterprise Drive, State College, PA 16801, USA: Minitab Inc, 1980.

5 Royal College of Physicians. Research on healthy volunteers. $\mathcal{F} R$ Coll Physicians Lond 1986;20:3-17.

6 Cockburn F, Dudgeon JA, Gairdner DMT, Jackson ADM for the British Paediatric Association. Guidelines to aid ethical committees considering research involving children. Arch Dis Child 1980;55:75-7.

7 British Paediatric Association. Guidelines for the ethical conduct of medical research involving children. London: BPA, conduct of 1992.

8 Mott MG, Chambers TL. Distress due to venepuncture. Lancet 1993;341:373. 